\title{
Association of glucose homeostasis measures with heart rate variability among Hispanic/Latino adults without diabetes: the Hispanic Community Health Study/Study of Latinos (HCHS/SOL)
}

Michelle L. Meyer ${ }^{1 *}$, Nathan M. Gotman ${ }^{1}$, Elsayed Z. Soliman², Eric A. Whitsel ${ }^{1}$, Raanan Arens ${ }^{3}$, Jianwen Cai ${ }^{1}$, Martha L. Daviglus ${ }^{4}$, Pablo Denes ${ }^{5}$, Hector M. González ${ }^{6}$, Juan Moreiras ${ }^{7}$, Gregory A. Talavera ${ }^{8}$ and Gerardo Heiss ${ }^{1}$

\begin{abstract}
Background: Reduced heart rate variability (HRV), a measure of cardiac autonomic function, is associated with an increased risk of cardiovascular disease (CVD) and mortality. Glucose homeostasis measures are associated with reduced cardiac autonomic function among those with diabetes, but inconsistent associations have been reported among those without diabetes. This study aimed to examine the association of glucose homeostasis measures with cardiac autonomic function among diverse Hispanic/Latino adults without diabetes.

Methods: The Hispanic community Health Study/Study of Latinos (HCHS/SOL; 2008-2011) used two-stage area probability sampling of households to enroll 16,415 self-identified Hispanics/Latinos aged 18-74 years from four USA communities. Resting, standard 12-lead electrocardiogram recordings were used to estimate the following ultrashortterm measures of HRV: RR interval (RR), standard deviation of all normal to normal RR (SDNN) and root mean square of successive differences in RR intervals (RMSSD). Multivariable regression analysis was used to estimate associations between glucose homeostasis measures with HRV using data from 11,994 adults without diabetes (mean age 39 years; $52 \%$ women).
\end{abstract}

Results: Higher fasting glucose was associated with lower RR, SDNN, and RMSSD. Fasting insulin and the homeostasis model assessment of insulin resistance was negatively associated with RR, SDNN, and RMSSD, and the association was stronger among men compared with women. RMSSD was, on average, $26 \%$ lower in men with higher fasting insulin and $29 \%$ lower in men with lower insulin resistance; for women, the corresponding estimates were smaller at 4 and $9 \%$, respectively. Higher glycated hemoglobin was associated with lower RR, SDNN, and RMSSD in those with abdominal adiposity, defined by sex-specific cut-points for waist circumference, after adjusting for demographics and medication use. There were no associations between glycated hemoglobin and HRV measures among those without abdominal adiposity.

Conclusions: Impairment in glucose homeostasis was associated with lower HRV in Hispanic/Latino adults without diabetes, most prominently in men and individuals with abdominal adiposity. These results suggest that reduced cardiac autonomic function is associated with metabolic impairments before onset of overt diabetes in certain

\footnotetext{
*Correspondence: mlmeyer@unc.edu

1 University of North Carolina at Chapel Hill, 137 E. Franklin St, Suite 306,

Chapel Hill, NC 27514, USA

Full list of author information is available at the end of the article
} 
subgroups, offering clues for the pathophysiologic processes involved as well as opportunity for identification of those at high risk before autonomic control is manifestly impaired.

Keywords: Autonomic function, Insulin resistance, Type 2 diabetes mellitus, Parasympathetic and sympathetic nervous system, Cohort study

\section{Background}

Metabolic dysregulation is associated with reduced cardiac autonomic function [1] and is implicated in the development of cardiac autonomic neuropathy among those with type 2 diabetes [2,3]. Cardiac autonomic function can be non-invasively measured by heart rate variability (HRV). Reduced HRV has been associated with cardiometabolic risk factors [4] and the metabolic syndrome [5-7], suggesting that autonomic dysfunction may occur before overt diabetes. In a murine model, diabetic and infarcted groups showed decreased HRV compared to controls [8].

Impairment in glucose homeostasis is associated with reduced autonomic function among people with diabetes $[4,9-12]$; however, the association has not been sufficiently examined among those without diabetes $[9,13]$. Prior studies did not include a comprehensive set of glucose homeostasis measures and were primarily among Caucasian samples. While Hispanic/Latino adults in the United States have a high burden of cardio metabolic risk factors [14], the metabolic syndrome [15], and high risk for diabetes [16], the association of glucose homeostasis measures and HRV has not been examined among Hispanic/Latino adults without diabetes.

The aim of this study, therefore, was to examine the associations of fasting insulin, fasting glucose, glycated hemoglobin $\left(\mathrm{HbA}_{1 \mathrm{c}}\right)$, and insulin resistance with cardiac autonomic function as estimated by ultra-short term measures of HRV among participants without diabetes in the Hispanic Community Health Study/Study of Latinos (HCHS/SOL). Understanding factors associated with HRV among this population with a high burden of cardiometabolic risk could provide insight into mechanisms of reduced cardiac autonomic function and the potential to identify individuals at risk for metabolic disease before autonomic control is manifestly impaired.

\section{Methods}

\section{Study cohort}

$\mathrm{HCHS} / \mathrm{SOL}$ is a multicenter epidemiologic cohort study examining chronic disease, risk and prevalence in 16,415 Hispanics/Latinos aged 18-74 years of Mexican, Central American, Cuban, Dominican, Puerto Rican, South American and other heritage groups. Details concerning the sampling strategy have been published elsewhere $[17,18]$. Briefly, the HCHS/SOL target population was defined as all non-institutionalized self-identified Hispanic/Latino adults aged 18-74 years residing in defined geographical areas (census block groups) at the following four field centers: Bronx, NY, Chicago, IL, Miami, FL, and San Diego, CA. Participants were selected from the target population using a two-stage area household probability sampling approach. Over-sampling at both stages of sample selection was used to increase the likelihood that a selected address yielded an eligible household and to increase the proportion of participants ages $45-74$ years $(\mathrm{n}=9714,59.2 \%)$. All participants provided written informed consent, and the study was approved by the Institutional Review Boards at all field centers, coordinating center, central labs, and reading centers.

Participants on whom an electrocardiogram (ECG) was not performed $(n=183)$, had diabetes $(n=2868)$, were using antiarrhythmic medication or self-reported using medication for abnormal heart rhythm $(n=265)$, were age $>75$ years $(n=7)$, or were missing information on key variables $(n=277)$ were excluded from the analysis. Key variables included Hispanic/Latino background, smoking status, waist circumference (WC), body mass index (BMI), fasting insulin, fasting glucose, and $\mathrm{HbA}_{1 \mathrm{c}}$. Additionally, guided by the current recommendations for measurement of HRV [19], we also excluded participants not in sinus rhythm or with rhythm disorders $(n=693)$, and low quality ECGs to ensure the accuracy and quality of the HRV measures $(n=128)$. Thus, these analyses are based on data from 11,994 participants (52\% women).

\section{Data collection}

Study examinations were conducted at field centers by certified study personnel following a standardized protocol. The details of the examination have been previously described [18]. In brief, participants were asked to fast, not smoke $12 \mathrm{~h}$ before the examination, refrain from vigorous physical activity the morning of the examination, and bring all prescription and nonprescription medication taken by them in the past 4 weeks. The medications were inventoried and therapeutically classified using a Master Drug Data Base (Medispan MDDB৫) supplemented with Spanish-language brand and generic name equivalents from Lexi-Comp Online ${ }^{\mathrm{TM}}$ and OVID॰ Martindale. Study personnel administered questionnaires to collect medical history, demographic factors, education, income, country of origin, length of residence in the 
United States, language preference, and lifestyle information. Anthropometric measurements included body weight $(\mathrm{kg})$, height $(\mathrm{cm}), \mathrm{WC}$ and calculated BMI. Three sitting blood pressure measurements were taken with an automatic sphygmomanometer (OMRON HEM-907 XL, Omron Healthcare Co. Ltd., Kyoto, Japan) after a 5 min rest and the last two measurements were averaged. Blood and urine specimens were collected and shipped to the HCHS/SOL Central Laboratory to be assayed, i.e. for total cholesterol, high-density lipoprotein, low-density lipoprotein, triglycerides, and fasting glucose and insulin. Hypertension was defined as systolic blood pressure $\geq 140 \mathrm{~mm} / \mathrm{Hg}$, diastolic blood pressure $\geq 90 \mathrm{~mm} / \mathrm{Hg}$, or self-reported use of anti-hypertensive medication. Diabetes was defined according to American Diabetes Association guidelines [20] as an $\mathrm{HbA}_{1 \mathrm{c} 0} \geq 6.5 \%$, post-oral glucose tolerance test glucose $\geq 200 \mathrm{mg} / \mathrm{dL}$, fasting glucose $\geq 126 \mathrm{mg} / \mathrm{dL}$, non-fasting glucose $\geq 200 \mathrm{mg} / \mathrm{dL}$, or self-reported use of anti-diabetic medication. Abdominal adiposity was defined as $W C \geq 102 \mathrm{~cm}$ for men and $\geq 88 \mathrm{~cm}$ for women. Prevalent coronary heart disease included ECG reports of possible myocardial infarction (major Q wave abnormalities and minor Q,QS waves with ST,T abnormalities) as well as self-report of heart attack or procedure (angioplasty, stent, bypass). Heart failure was self-reported, but not conformed.

\section{Electrocardiography}

Resting, standard, 12-lead, 10 s ECGs were recorded following a standardized protocol. The participants were supine, breathing freely, and instructed not to talk during the recording. Study personnel positioned the electrodes using a chest electrode locator [21, 22]. ECGs were recorded using the GE MAC 1200 electrograph (GE, Milwaukee, Wisconsin) with a $10 \mathrm{~mm} / \mathrm{mV}$ calibration at a speed of $25 \mathrm{~mm} / \mathrm{s}$. The Epidemiology Cardiology Research Center (EPICARE; Wake Forest School of Medicine, Winston Salem, NC) centrally processed the ECGs using the GE 12-SL Marquette Version 2001 (GE, Milwaukee, Wisconsin).

The automatically calculated ultra-short term, time domain measures of HRV included the median duration of the RR interval across all twelve leads as computed from heart rate, RR (ms) $=60,000 \mathrm{~ms} /$ heart rate (bpm); the standard deviation of all normal to normal RR intervals that indicates total HRV, SDNN $(\mathrm{ms})=\left\{\left[\sum_{\mathrm{j}=1}^{\mathrm{n}}\left(\mathrm{RR}_{\text {mean }}-\mathrm{RR}_{\mathrm{j}}\right)^{2}\right] /(\mathrm{n}-1)\right\}^{0.5} \quad$ and the root mean square of successive differences in all normal to normal RR intervals that indicates the degree the RR interval changes between adjacent beats, $\operatorname{RMSSD}(m s)=\left\{\left[\sum_{\mathrm{j}=1}^{\mathrm{n}}\left(\mathrm{RR}_{\mathrm{j}+1}-\mathrm{RR}_{\mathrm{j}}\right)^{2}\right] / \mathrm{n}\right\}^{0.5}$.

\section{Statistical methods}

All analyses used complex survey methods and were weighted to account for design effects, cluster sampling and the use of stratification in sample selection [18]. Means and prevalence rates are therefore presented as weighted statistics to adjust for potential bias due to differential nonresponse at the household and person levels. We estimated the mean and $95 \%$ confidence interval (CI) of RMSSD, SDNN and RR interval by demographic characteristics, and quartiles of glucose homeostasis measures stratified by sex. Following the recommendations of Rothman [23], effect sizes and confidence intervals were presented in place of $\mathrm{p}$ values and significance testing.

Multivariable linear regression analyses were used to estimate associations between exposures (fasting insulin, fasting glucose, $\mathrm{HbA}_{1 \mathrm{c}}$, and insulin resistance computed according to the homeostasis model assessment of insulin resistance (HOMA-IR)) and outcomes (SDNN, RMSSD and RR). Separate models were constructed for each exposure-outcome pair and exposures were not adjusted for other glucose homeostasis measures. The adjustment variables considered in all models included sex, age groups $(18-24,25-34,35-44,45-54,55-64$, and $65+$ years old), Hispanic/Latino background, field center, continuous BMI, continuous waist circumference, current smoking, heart rate modifying drugs (beta-blockers, non-hydropyridine calcium channel blockers, and sympathomimetics), and the interactions between glucose homeostasis measures with gender, age and abdominal adiposity. In sensitivity analyses, we adjusted for selfreported physical activity and alcohol consumption. For simplicity, interactions were selected based on model fit using adjusted $R^{2}$ values for RMSSD. Interactions were selected if adjusted $R^{2}$ values increased model fit by at least 0.001 . When interaction terms were selected, we reported stratified results. For $\mathrm{HbA}_{1 \mathrm{c}}$, the waist circumference interaction was selected but categorized as $W C \geq 102 \mathrm{~cm}$ for men and $\geq 88 \mathrm{~cm}$ for women to indicate abdominal adiposity for ease of interpretation. For anthropometric measures, WC was chosen as a covariate based on a slightly higher adjusted $R^{2}$ value compared with the model with BMI (difference in adjusted $\mathrm{R}^{2} \approx 0.00013$ ). The best fitting models for SDNN were similar and the same model was used for RR interval for comparability. Analyses were conducted using complex survey procedures in SAS (version 9.3, SAS Institute, Inc., Cary, NC) and SUDAAN (release 11.0.0, Research Triangle Institute, Research Triangle Park, NC).

\section{Results}

About half of the HCHS/SOL target population for this study was comprised of women and the mean age was 38.8 years (Table 1). Almost $37 \%$ of the $\mathrm{HCHS} / \mathrm{SOL}$ 
Table 1 Demographic characteristics

\begin{tabular}{|c|c|c|c|}
\hline Characteristic & $\mathbf{N}$ & $\%$ or Mean & $95 \% \mathrm{Cl}$ \\
\hline Male (\%) & 4833 & 48.11 & $(46.79,49.42)$ \\
\hline \multicolumn{4}{|l|}{ Age group (\%) } \\
\hline $18-24$ & 1444 & 18.94 & $(17.73,20.21)$ \\
\hline $25-34$ & 1819 & 24.63 & $(23.25,26.06)$ \\
\hline $35-44$ & 2461 & 23.03 & $(21.81,24.30)$ \\
\hline $45-54$ & 3562 & 18.01 & $(17.03,19.02)$ \\
\hline $55-64$ & 2106 & 10.34 & $(9.61,11.12)$ \\
\hline $65+$ & 602 & 5.05 & $(4.47,5.70)$ \\
\hline \multicolumn{4}{|l|}{ Hispanic background (\%) } \\
\hline Mexican/Mexican American & 4784 & 38.13 & $(34.90,41.46)$ \\
\hline Puerto Rican & 1809 & 15.09 & $(13.58,16.74)$ \\
\hline Cuban & 1753 & 19.61 & $(16.54,23.08)$ \\
\hline Dominican & 1084 & 10.02 & $(8.68,11.55)$ \\
\hline Central American & 1320 & 7.59 & $(6.48,8.86)$ \\
\hline South American & 854 & 5.28 & $(4.63,6.02)$ \\
\hline Other & 390 & 4.28 & $(3.68,4.96)$ \\
\hline Body mass index (BMl; kg/m²) & & 28.88 & $(28.68,29.08)$ \\
\hline Waist circumference (cm) & & 95.90 & $(95.44,96.36)$ \\
\hline Obese $\left(\mathrm{BMI} \geq 30 \mathrm{~kg} / \mathrm{m}^{2}\right)$ & 4597 & 36.86 & $(35.37,38.38)$ \\
\hline Abdominal adiposity & 6818 & 51.44 & $(49.82,53.05)$ \\
\hline Systolic blood pressure (mmHg) & & 118.32 & $(117.85,118.79)$ \\
\hline Diastolic blood pressure (mmHg) & & 71.79 & $(71.43,72.15)$ \\
\hline Fasting glucose (mg/dL) & & 93.51 & $(93.28,93.74)$ \\
\hline Fasting insulin (mU/L) & & 12.06 & $(11.78,12.34)$ \\
\hline $\mathrm{HbA}_{1 \mathrm{c}}(\%)$ & & 5.41 & $(5.40,5.42)$ \\
\hline HOMA-IR (index) & & 2.83 & $(2.76,2.90)$ \\
\hline Current smoking & 2382 & 21.86 & $(20.60,23.17)$ \\
\hline Coronary heart disease & 416 & 3.19 & $(2.71,3.75)$ \\
\hline Self-reported heart failure & 132 & 0.87 & $(0.68,1.10)$ \\
\hline Beta blocker use & 520 & 3.24 & $(2.86,3.66)$ \\
\hline $\begin{array}{l}\text { Non-hydropyridine calcium channel } \\
\text { blocker use }\end{array}$ & 300 & 1.98 & $(1.63,2.41)$ \\
\hline Sympathomimetic medication use & 441 & 3.50 & $(3.01,4.07)$ \\
\hline
\end{tabular}

The Hispanic Community Health Study/Study of Latinos (HCHS/SOL) baseline examination (2008-2011)

Abdominal adiposity (waist circumference $\geq 102 \mathrm{~cm}$ for men and $\geq 88 \mathrm{~cm}$ for women)

target population was obese and $51 \%$ had abdominal adiposity. Individuals of Mexican background were the largest Hispanic/Latino background group at $38 \%$ of the HCHS/SOL target population. Men had an $8 \%$ lower mean RMSSD, similar SDNN, and $4 \%$ higher RR compared with women (Table 2). Individuals taking beta-blockers and non-hydropyridine calcium channel blockers had 35-66 \% higher mean RMSSD and SDNN than non-users, but those taking beta-blockers had a $5 \%$ lower mean RR. Mean RMSSD and SDNN was lower by $53-56 \%$ between age groups $18-24$ and $65+$ years. All measures were 4-11\% lower among those without abdominal adiposity versus those with abdominal adiposity. Those with obesity had $4 \%$ lower RR but similar RMSSD and SDNN versus non-obese individuals.

HRV and RR varied by quartiles of glucose homeostasis measures (Fig. 1). Trends for RMSSD and SDNN were very similar. Comparing those in quartile 4 to those in quartile 1 for fasting insulin and HOMA-IR, the mean RMSSD was 27 and $29 \%$ lower, respectively, among men. But for women, the mean differences were much smaller ( 4 and $9 \%$, Fig. 1). Comparing those in quartile 4 to those in quartile 1 of fasting glucose, the mean RMSSD was $27 \%$ lower in men and $29 \%$ lower in women. Trends for SDNN were similar to those of RMSSD. Subgroup trend differences for RR interval were much less pronounced. For example, comparing those in quartile 4 to those in quartile 1 of fasting insulin, the mean RR interval was lower by $10 \%$ in men and $8 \%$ in women.

After adjustment for gender, age, Hispanic/Latino background, field center, and medication use, the association of fasting glucose with RMSSD was greatly reduced (from -0.65 to $-0.20 \mathrm{~mm}$ change in RMSSD for each $\mathrm{mg} / \mathrm{dL}$ increase in fasting glucose; Table 3$)$. The association of fasting glucose with RR was more pronounced after adjustment for all covariates $(\beta=-1.55$ vs -0.80). Fasting insulin was negatively associated with all HRV measures, and the association was stronger among men compared with women. The multivariable models for fasting insulin were similar to unadjusted models $(\beta=-0.45$ vs $\beta=-0.44$ for men, $\beta=-0.06$ vs $\beta=-0.14$ for women). $\mathrm{HbA}_{1 \mathrm{c}}$ was negatively associated with RMSSD among individuals with abdominal adiposity, defined by sex-specific cut-points for WC, but not among those without abdominal adiposity. While the unadjusted subgroup effects for $\mathrm{HbA}_{1 \mathrm{c}}$ were similar for individuals with and without abdominal adiposity, after adjusting for gender, age, Hispanic/Latino background, field center, and medication use, differences in subgroups emerged for all HRV measures. The association of $\mathrm{HbA}_{1 \mathrm{c}}$ and SDNN were similar to that of RMSSD. After adjustment, there was little or no association between $\mathrm{HbA}_{1 \mathrm{c}}$ and $\mathrm{RR}$ among those without abdominal adiposity, but there was a $22.9 \mathrm{~ms}$ decrease in $\mathrm{RR}$ for each unit increase in $\mathrm{HbA}_{1 \mathrm{c}}$ among those with abdominal adiposity. As with fasting insulin, HOMA-IR was associated with all HRV measures in both men and women, but the association was slightly stronger among men. Adjusting for physical activity and current weekly alcohol consumption did not alter the results (data not shown).

\section{Discussion}

Our study contributes new information to the field by evaluating the cross-sectional association of multiple 
Table 2 Mean and $95 \%$ confidence interval (CI) of RMSSD, SDNN and RR interval by demographic characteristics

\begin{tabular}{|c|c|c|c|c|c|c|}
\hline \multirow[t]{2}{*}{ Characteristic } & \multicolumn{2}{|c|}{ RMSSD (ms) } & \multicolumn{2}{|c|}{ SDNN (ms) } & \multicolumn{2}{|c|}{$\mathrm{RR}(\mathrm{ms})$} \\
\hline & Mean & $95 \% \mathrm{Cl}$ & Mean & $95 \% \mathrm{Cl}$ & Mean & $95 \% \mathrm{Cl}$ \\
\hline \multicolumn{7}{|l|}{ Sex (\%) } \\
\hline Male & 40.72 & $(39.07,42.38)$ & 34.20 & $(32.98,35.43)$ & 1010 & $(1003,1016)$ \\
\hline Female & 44.43 & $(43.08,45.78)$ & 35.34 & $(34.36,36.32)$ & 968 & $(963,973)$ \\
\hline \multicolumn{7}{|l|}{ Age group (\%) } \\
\hline $18-24$ & 63.33 & $(59.82,66.85)$ & 49.20 & $(46.76,51.64)$ & 981 & $(971,991)$ \\
\hline $25-34$ & 50.37 & $(48.22,52.52)$ & 40.30 & $(38.61,41.98)$ & 988 & $(978,998)$ \\
\hline $35-44$ & 37.56 & $(36.14,38.97)$ & 31.41 & $(30.27,32.55)$ & 985 & $(976,993)$ \\
\hline $45-54$ & 30.32 & $(29.38,31.26)$ & 26.13 & $(25.39,26.87)$ & 994 & $(987,1001)$ \\
\hline $55-64$ & 26.51 & $(25.39,27.63)$ & 23.59 & $(22.59,24.58)$ & 992 & $(984,1001)$ \\
\hline $65+$ & 27.59 & $(24.63,30.54)$ & 23.20 & $(20.71,25.68)$ & 1006 & $(991,1022)$ \\
\hline \multicolumn{7}{|c|}{ Obese $\left(\mathrm{BMI} \geq 30 \mathrm{~kg} / \mathrm{m}^{2}\right)$} \\
\hline Yes & 43.49 & $(42.09,44.89)$ & 35.55 & $(34.50,36.61)$ & 1001 & $(996,1006)$ \\
\hline No & 41.20 & $(39.33,43.08)$ & 33.49 & $(32.22,34.76)$ & 966 & $(959,973)$ \\
\hline \multicolumn{7}{|c|}{ Abdominal adiposity } \\
\hline Yes & 44.50 & $(42.92,46.08)$ & 36.64 & $(35.44,37.83)$ & 1010 & $(1004,1016)$ \\
\hline No & 40.89 & $(39.37,42.42)$ & 33.05 & $(31.98,34.13)$ & 967 & $(962,973)$ \\
\hline \multicolumn{7}{|l|}{ Current smoking } \\
\hline Yes & 42.07 & $(40.96,43.17)$ & 34.22 & $(33.44,35.01)$ & 985 & $(981,990)$ \\
\hline No & 44.72 & $(41.75,47.68)$ & 36.83 & $(34.63,39.02)$ & 998 & $(988,1009)$ \\
\hline \multicolumn{7}{|l|}{ Beta blocker use } \\
\hline Yes & 43.14 & $(41.97,44.30)$ & 35.24 & $(34.40,36.07)$ & 987 & $(982,991)$ \\
\hline No & 31.91 & $(28.80,35.01)$ & 24.84 & $(22.65,27.03)$ & 1042 & $(1024,1060)$ \\
\hline \multicolumn{7}{|c|}{ Non-hydropyridine calcium channel blocker use } \\
\hline Yes & 43.11 & $(41.96,44.27)$ & 35.16 & $(34.33,35.98)$ & 989 & $(984,993)$ \\
\hline No & 25.92 & $(22.42,29.42)$ & 22.14 & $(19.73,24.56)$ & 981 & $(959,1003)$ \\
\hline \multicolumn{7}{|c|}{ Sympathomimetic medication use } \\
\hline Yes & 42.76 & $(41.62,43.91)$ & 34.88 & $(34.07,35.69)$ & 990 & $(986,995)$ \\
\hline No & 43.04 & $(33.48,52.59)$ & 35.45 & $(28.13,42.78)$ & 936 & $(917,954)$ \\
\hline
\end{tabular}

Cl confidence interval, RMSSD root mean square of successive differences in RR intervals, SDNN standard deviation of all normal to normal RR intervals, $R R$ median duration of the RR interval, $B M /$ body mass index

Abdominal adiposity (waist circumference $\geq 102 \mathrm{~cm}$ for men and $\geq 88 \mathrm{~cm}$ for women)

glucose homeostasis measures with cardiac autonomic function in a diverse population of Hispanic/Latino adults. In this cross-sectional study, higher fasting glucose was associated with lower HRV, as assessed by several HRV measures, in all subgroups; higher fasting insulin and HOMA-IR were associated with lower HRV particularly in men; and higher $\mathrm{HbA}_{1 \mathrm{c}}$ was associated with lower HRV in individuals with abdominal adiposity. These results suggest that reduced cardiac autonomic function occurs among those with metabolic impairments even before the onset of overt diabetes. The association was more pronounced among men and those with abdominal adiposity, defined by sex-specific cut-points for waist circumference.
Prior studies of glucose homeostasis measures and cardiac autonomic function

Our findings are in agreement with prior studies among people without diabetes showing associations between glucose homeostasis measures with reduced cardiac autonomic function, although results are inconsistent across glucose homeostasis measures [4, 5, 9, 13]. The atherosclerosis risk in communities study reported weak, inverse cross-sectional associations between fasting glucose and insulin quintiles with RMSSD and RR among people without diabetes [9]. Insulin quintiles were negatively associated with SDNN, whereas no associations were seen between glucose quintiles and SDNN. In contrast, fasting glucose was negatively associated with 
a

Men
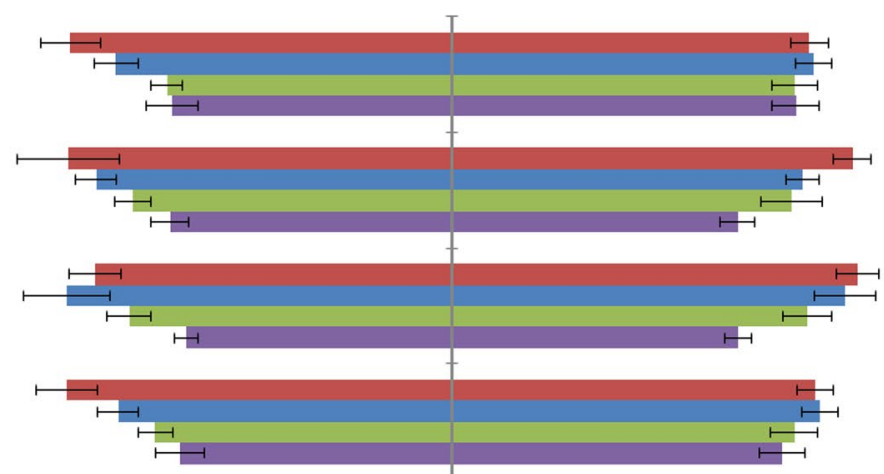

60

40
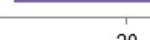

RMSSD (ms)

b

Men

Women

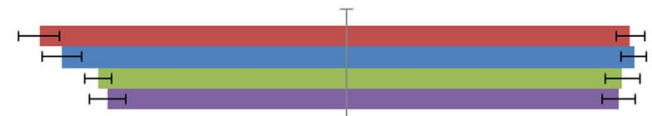

Fasting Insulin

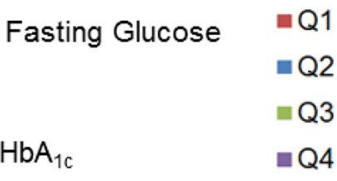

HOMA-IR

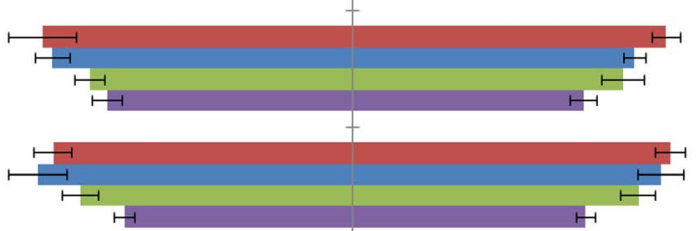

Fasting Glucose

घ1

ㄴ2

= $\mathrm{Q3}$

$\mathrm{HbA}_{1 \mathrm{c}}$

- $\mathrm{Q} 4$

HOMA-IR

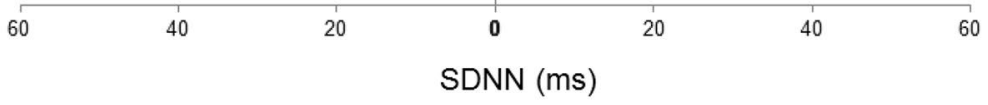

C

Men

Women

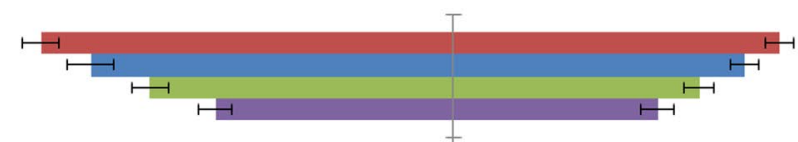

Fasting Insulin

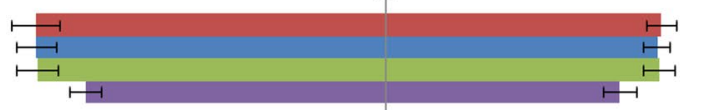

Fasting Glucose

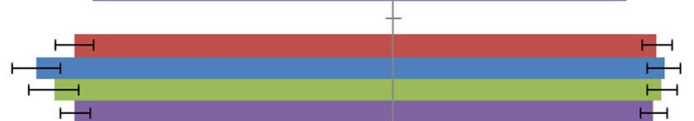

$\begin{aligned} & \approx \mathrm{Q} 2 \\ \mathrm{HbA}_{1 \mathrm{c}} & \approx \mathrm{Q} 3 \\ & \approx \mathrm{Q} 4\end{aligned}$

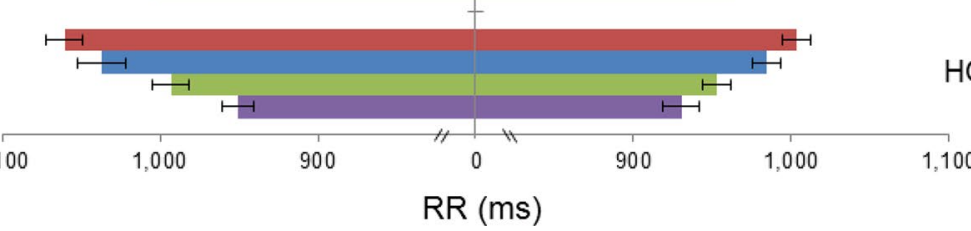

Fig. 1 Mean ( $95 \%$ confidence interval) of a RMSSD, b SDNN, and c RR by quartiles (Q) of glycemic homeostasis marker stratified by sex. Values are Q1 (lowest) to Q4 (highest). RMSSD root mean square of successive differences in RR intervals, SDNN standard deviation of all normal to normal RR intervals, RR median duration of the RR interval; $H b A_{1 c}$ glycated hemoglobin, HOMA-IR homeostasis model assessment of insulin resistance 
Table 3 Adjusted associations of glucose homeostasis markers with RMSSD, SDNN and RR interval

\begin{tabular}{|c|c|c|c|c|c|c|}
\hline \multirow[t]{2}{*}{ Outcome/exposure } & \multicolumn{2}{|c|}{ Unadjusted } & \multicolumn{2}{|c|}{ Model $1^{a}$} & \multicolumn{2}{|c|}{ Model $2^{b}$} \\
\hline & $\bar{\beta}$ & $95 \% \mathrm{Cl}$ & $\beta$ & $95 \% \mathrm{Cl}$ & $\beta$ & $95 \% \mathrm{Cl}$ \\
\hline \multicolumn{7}{|l|}{ RMSSD (ms) } \\
\hline Fasting glucose (mg/dL) & -0.65 & $(-0.77,-0.53)$ & -0.20 & $(-0.33,-0.07)$ & -0.16 & $(-0.28,-0.05)$ \\
\hline Fasting insulin $(\mathrm{mU} / \mathrm{L})$, men & -0.45 & $(-0.66,-0.24)$ & -0.43 & $(-0.62,-0.24)$ & -0.44 & $(-0.62,-0.26)$ \\
\hline Fasting insulin $(\mathrm{mU} / \mathrm{L})$, women & -0.06 & $(-0.20,0.08)$ & -0.13 & $(-0.24,-0.01)$ & -0.14 & $(-0.27,-0.01)$ \\
\hline $\mathrm{HbA}_{1 c^{\prime}}$ no abdominal adiposity & -12.8 & $(-15.83,-9.78)$ & 3.61 & $(0.26,6.97)$ & 3.22 & $(-0.09,6.53)$ \\
\hline $\mathrm{HbA}_{1,}$ abdominal adiposity & -16.5 & $(-20.09,-13.04)$ & -3.57 & $(-6.74,-0.41)$ & -3.62 & $(-6.75,-0.48)$ \\
\hline HOMA-IR, men & -1.88 & $(-2.71,-1.05)$ & -1.65 & $(-2.37,-0.92)$ & -1.66 & $(-2.34,-0.97)$ \\
\hline HOMA-IR, women & -0.49 & $(-1.03,0.06)$ & -0.55 & $(-1.03,-0.07)$ & -0.58 & $(-1.10,-0.06)$ \\
\hline \multicolumn{7}{|l|}{ SDNN (ms) } \\
\hline Fasting glucose (mg/dL) & -0.43 & $(-0.52,-0.34)$ & -0.13 & $(-0.23,-0.04)$ & -0.10 & $(-0.20,-0.01)$ \\
\hline Fasting insulin (mU/L), men & -0.29 & $(-0.44,-0.15)$ & -0.28 & $(-0.41,-0.15)$ & -0.26 & $(-0.38,-0.13)$ \\
\hline Fasting insulin (mU/L), women & -0.05 & $(-0.15,0.05)$ & -0.10 & $(-0.19,-0.01)$ & -0.08 & $(-0.18,0.02)$ \\
\hline $\mathrm{HbA}_{1 c}$, no abdominal adiposity & -9.11 & $(-11.44,-6.78)$ & 2.29 & $(-0.20,4.77)$ & 1.98 & $(-0.48,4.44)$ \\
\hline $\mathrm{HbA}_{1 c}$ abdominal adiposity & -11.8 & $(-14.42,-9.26)$ & -2.56 & $(-4.94,-0.19)$ & -2.60 & $(-4.96,-0.23)$ \\
\hline HOMA-IR, men & -1.23 & $(-1.79,-0.67)$ & -1.07 & $(-1.56,-0.58)$ & -0.97 & $(-1.44,-0.49)$ \\
\hline HOMA-IR, women & -0.37 & $(-0.77,0.03)$ & -0.43 & $(-0.79,-0.06)$ & -0.35 & $(-0.77,0.06)$ \\
\hline \multicolumn{7}{|l|}{$\mathrm{RR}(\mathrm{ms})$} \\
\hline Fasting glucose (mg/dL) & -0.80 & $(-1.29,-0.31)$ & -2.02 & $(-2.52,-1.52)$ & -1.55 & $(-2.06,-1.04)$ \\
\hline Fasting insulin $(\mathrm{mU} / \mathrm{L})$, men & -4.41 & $(-5.13,-3.69)$ & -4.39 & $(-5.11,-3.67)$ & -4.09 & $(-4.90,-3.29)$ \\
\hline Fasting insulin (mU/L), women & -3.15 & $(-3.94,-2.36)$ & -3.07 & $(-3.80,-2.34)$ & -2.82 & $(-3.54,-2.09)$ \\
\hline $\mathrm{HbA}_{1 c^{\prime}}$ no abdominal adiposity & 19.58 & $(2.84,36.32)$ & 1.03 & $(-16.54,18.61)$ & -0.33 & $(-17.83,17.18)$ \\
\hline $\mathrm{HbA}_{1 c^{\prime}}$ abdominal adiposity & -8.18 & $(-20.46,4.11)$ & -22.8 & $(-35.12,-10.55)$ & -22.9 & $(-35.24,-10.72)$ \\
\hline HOMA-IR, men & -17.2 & $(-20.07,-14.46)$ & -17.3 & $(-20.15,-14.47)$ & -16.0 & $(-19.18,-12.93)$ \\
\hline HOMA-IR, women & -12.8 & $(-15.70,-10.03)$ & -12.6 & $(-15.32,-10.03)$ & -11.5 & $(-14.17,-8.91)$ \\
\hline
\end{tabular}

Abdominal adiposity (waist circumference $\geq 102 \mathrm{~cm}$ for men and $\geq 88 \mathrm{~cm}$ for women)

$R M S S D$ root mean square of successive differences in RR intervals, SDNN standard deviation of all normal to normal RR intervals, RR median duration of the RR interval, $\mathrm{HbA}_{1 \mathrm{c}}$ glycated hemoglobin, $\mathrm{HOMA}-\mathrm{IR}$ homeostasis model assessment of insulin resistance

a Model 1 includes gender, age groups (each as an indicator variable), Hispanic background, and medications: $\beta$-blocker, non-hydropyridine calcium channel blocker, sympathomimetics, and field center

${ }^{b}$ For fasting glucose, fasting insulin, and HOMA-IR, model 2 includes model 1 plus current smoking and waist circumference. For $\mathrm{HbA}_{1 \mathrm{C}}$ model 2 includes model 1 plus current smoking

SDNN and positively associated with heart rate, but not associated with RMSSD in a study among participants with normal fasting glucose levels [5]. In a healthy cohort free of diabetes, fasting insulin and fasting glucose levels were associated with reduced cardiac autonomic function measured by baroreflex sensitivity, but the association with fasting glucose was no longer significantly associated after adjusting for age, blood pressure and body mass index [13]. The patterns as reported above include HRV measured from 2 min to 24 h ECGs, and are similar to our results from $10 \mathrm{~s}$ ECGs. However, both fasting insulin and fasting glucose levels were associated with lower RMSSD, SDNN and RR in this study, with stronger associations among subgroups.
We add to the literature by reporting on the associations between $\mathrm{HbA}_{1 \mathrm{c}}$ and HOMA-IR with reduced heart rate variability. A study among participants with normal fasting glucose levels showed that only $\mathrm{HbA}_{1 \mathrm{c}}$ was associated with reduced cardiac autonomic function defined as the lowest 25th percentile for SDNN and baroreflex sensitivity [4]. No associations were observed between fasting insulin and fasting glucose with SDNN and mean $\mathrm{NN}$ (RR interval). We found that $\mathrm{HbA}_{1 \mathrm{c}}$ was associated with RMSSD, SDNN and RR among those with abdominal adiposity (WC $\geq 102 \mathrm{~cm}$ for men and $\geq 88 \mathrm{~cm}$ for women), but no associations were observed among individuals with waist circumferences below the sex-specific cut-points. Discrepancies in the association between 
measures of glucose metabolism and HRV between prior studies and our results could be related to differences in HRV methodology and the study populations since previous studies involved mostly older Caucasian participants. Additionally, there were no reports of whether the investigators examined effect modification by sex or adiposity.

\section{Potential mechanisms of the sex differences in glucose homeostasis and cardiac autonomic function}

There was a stronger association between fasting insulin and HOMA-IR with HRV among men compared with women. Sex differences in HRV among those without diabetes have not been well studied, but evidence among those with diabetes suggests that there are sex differences in nerve conduction [24]. Men tend to present symptoms of diabetic neuropathy earlier than women [25], and might be more susceptible to autonomic failure (as defined by e.g. low HRV) compared with women [26, 27]. These observations indicate that men have earlier or stronger manifestations of reduced cardiac autonomic function compared with women, which could explain the effect modification by sex observed in this study.

\section{Abdominal adiposity in cardiac autonomic function}

$\mathrm{HbA}_{1 \mathrm{c}}$ was only associated with HRV measures among those with abdominal adiposity defined as a high waist circumference. This is consistent with previous studies showing that visceral, or central, adipose tissue is more strongly associated with metabolic dysregulation, muscle sympathetic nerve activity [28, 29], autonomic nervous system activity [30], and HR [31]. The adipokine leptin is associated with autonomic dysfunction [32, 33], and may be stronger among those with higher levels of adiposity [34]. $\mathrm{HbA}_{1 \mathrm{c}}$ is a time-integrated marker of long-term glucose exposure, thus the observed association suggests that those with abdominal obesity and poor glycemic control are prone to have lower cardiac autonomic function, although we were not able to evaluate such a complex relationship in this cross-sectional analysis.

\section{Glucose homeostasis measures and modulation of cardiac autonomic function}

The observed associations between glucose homeostasis measures with SDNN, RMSSD and RR suggest that insulin resistance and impaired glycemic control adversely affect autonomic function; however, the temporal relationship between insulin resistance and poor glucose control with reduced cardiac autonomic activity has not been elucidated. Several mechanisms have been implicated in the link between glucose homeostasis measures with reduced autonomic function. Insulin resistance could cause reduced autonomic function by triggering sympathetic nervous system activity $[35,36]$, suppressing vagal cardiac activity [37], and regulating energy balance and homeostasis [38-41]. An enhanced formation of advanced glycation end products and their associated cross-linking molecules [42] is also reported to be associated with autonomic nerve impairment and neuropathy in individuals with diabetes [43]. Although the mechanisms that contribute to reduced cardiac autonomic function are not fully characterized, the evidence above indicates that insulin resistance and glucose metabolism are central factors.

\section{Limitations}

Our study had limitations that should be noted. We used ultra-short HRV measures without control for respiration. Although guidelines from the Task Force of the European Society of Cardiology the North American Society of Pacing Electrophysiology recommend a 5-min recording for time domain HRV indices [19], ultra-short term measures of HRV have been shown to have high reproducibility [44] and their predictive validity has been described [45-50]. Time limitations precluded the acquisition of ECG records of longer duration, therefore only time domain indices were available. Thus, frequency domain indices to distinguish parasympathetic and sympathetic modulation of cardiac autonomic activity and geometric measures that would allow for the assessment of different geometrical forms were not attempted. Lastly, we are unable to address the temporality of the observed associations given the cross-sectional nature of these analyses.

\section{Conclusions}

A comprehensive set of glucose homeostasis measures were associated with reduced autonomic activity in some subgroups of Hispanic/Latino adults without diabetes. The associations were stronger among men and in those with abdominal adiposity, offering clues for the pathophysiologic processes involved as well as opportunity for identification of those at high risk before autonomic control is manifestly impaired. While screening for reduced cardiac autonomic function is recommended for risk assessment in persons with diabetes, our results suggest that impairment in glucose homeostasis is associated with lower autonomic activity even before diabetes becomes clinically manifest. The longitudinal follow-up of this population can be expected to offer insights into the temporal relationships of glucose homeostasis measures with HRV, and its utility in risk stratification.

\section{Abbreviations}

BMl: body mass index; Cl: confidence interval; CVD: cardiovascular disease; ECG: electrocardiogram; $\mathrm{HbA}_{1 c}$ : glycated hemoglobin; $\mathrm{HCHS} / \mathrm{SOL}$ : The Hispanic Community Health Study/Study of Latinos; HOMA-IR: homeostasis 
model assessment of insulin resistance; HRV: heart rate variability; RMSSD: root mean square of successive differences in RR intervals; RR: RR interval; SDNN: standard deviation of all normal to normal RR intervals; WC: waist circumference.

\section{Authors' contributions}

MLM, NMG, EZS, EAW, and GH contributed to the execution and analysis of this study. MLM, NMG, EZS, EAW, RA, JC, MLD, PD, HMG, JM, GAT, and GH contributed to the planning of the manuscript, interpretation of the results, and directly participated in writing of this manuscript. All authors read and approved the final manuscript.

\section{Author details \\ ${ }^{1}$ University of North Carolina at Chapel Hill, 137 E. Franklin St, Suite 306, Chapel Hill, NC 27514, USA. ${ }^{2}$ Wake Forest School of Medicine, Winston Salem, NC, USA. ${ }^{3}$ Division of Respiratory and Sleep Medicine, The Children's Hospital at Montefiore, Albert Einstein College of Medicine, Bronx, NY, USA. ${ }^{4}$ University of Illinois at Chicago College of Medicine, Chicago, IL, USA. ${ }^{5}$ Northwestern University, Chicago, IL, USA. ${ }^{6}$ Michigan State University, East Lansing, MI, USA ${ }^{7}$ University of Miami, Coral Gables, FL, USA. ${ }^{8}$ San Diego State University, San Diego, CA, USA.}

\section{Acknowledgements}

Funding/Support: The Hispanic Community Health Study/Study of Latinos was carried out as a collaborative study supported by contracts from the National Heart, Lung, and Blood Institute (NHLBI) to the University of North Carolina (N01-HC65233), University of Miami (N01-HC65234), Albert Einstein College of Medicine (N01-HC65235), Northwestern University (N01-HC65236), and San Diego State University (N01-HC65237). The following institutes, centers, or offices contribute to the HCHS/SOL through a transfer of funds to the NHLBI: National Center on Minority Health and Health Disparities, the National Institute on Deafness and Other Communications Disorders, the National Institute of Dental and Craniofacial Research, the National Institute of Diabetes and Digestive and Kidney Diseases, the National Institute of Neurological Disorders and Stroke, and the Office of Dietary Supplements. MLM was supported by the NHLBI T32 training Grant HL-007055. HMG was supported by the National Institute of Aging (AG48642).

The authors thank the staff and participants of $\mathrm{HCHS} / \mathrm{SOL}$ for their important contributions. A complete list of staff and investigators was published in Ann Epidemiol. 2010;20:642-649 and is also available on the study website, http:// www.cscc.unc.edu/hchs/.

Role of the Sponsor: The funding agency had a role in the design and conduct of the study; in the collection, analysis, and interpretation of the data; and in the review and approval of the manuscript.

\section{Competing interests}

The authors declare that they have no competing interests.

\section{Received: 31 December 2015 Accepted: 9 March 2016} Published online: 16 March 2016

\section{References}

1. Tentolouris N, Argyrakopoulou G, Katsilambros N. Perturbed autonomic nervous system function in metabolic syndrome. Neuro Mol Med. 2008;10(3):169-78.

2. Vinik Al, Maser RE, Mitchell BD, Freeman R. Diabetic autonomic neuropathy. Diabetes Care. 2003;26(5):1553-79.

3. Carnethon MR, Golden SH, Folsom AR, Haskell W, Liao D. Prospective investigation of autonomic nervous system function and the development of type 2 diabetes: the atherosclerosis risk in communities study, 1987-1998. Circulation. 2003;107(17):2190-5.

4. Gerritsen J, Dekker JM, TenVoorde BJ, Bertelsmann FW, Kostense PJ, Stehouwer CD, et al. Glucose tolerance and other determinants of cardiovascular autonomic function: the Hoorn Study. Diabetologia. 2000:43(5):561-70.

5. Stein PK, Barzilay Jl, Domitrovich PP, Chaves PM, Gottdiener JS, Heckbert $\mathrm{SR}$, et al. The relationship of heart rate and heart rate variability to non-diabetic fasting glucose levels and the metabolic syndrome: the cardiovascular health study. Diabet Med. 2007;24(8):855-63.

6. Min KB, Min JY, Paek D, Cho SI. The impact of the components of metabolic syndrome on heart rate variability: using the NCEP-ATP III and IDF definitions. Pacing Clin Electrophysiol. 2008;31(5):584-91.

7. Koskinen T, Kahonen M, Jula A, Mattsson N, Laitinen T, KeltikangasJarvinen $L$, et al. Metabolic syndrome and short-term heart rate variability in young adults. The cardiovascular risk in young Finns study. Diabet Med. 2009;26(4):354-61.

8. Malfitano C, Barboza CA, Mostarda C, da Palma RK, dos Santos CP, Rodrigues $B$, et al. Diabetic hyperglycemia attenuates sympathetic dysfunction and oxidative stress after myocardial infarction in rats. Cardiovascular diabetology. 2014;13:131.

9. Schroeder EB, Chambless LE, Liao D, Prineas RJ, Evans GW, Rosamond WD, et al. Diabetes, glucose, insulin, and heart rate variability: the atherosclerosis risk in communities (ARIC) study. Diabetes Care. 2005;28(3):668-74.

10. Ziegler D, Zentai C, Perz S, Rathmann W, Haastert B, Meisinger C, et al. Selective contribution of diabetes and other cardiovascular risk factors to cardiac autonomic dysfunction in the general population. Exp Clin Endocrinol Diabetes. 2006;114(4):153-9.

11. Perciaccante A, Fiorentini A, Paris A, Serra P, Tubani L. Circadian rhythm of the autonomic nervous system in insulin resistant subjects with normoglycemia, impaired fasting glycemia, impaired glucose tolerance, type 2 diabetes mellitus. BMC cardiovasc Disord. 2006;6:19.

12. Singh JP, Larson MG, O'Donnell CJ, Wilson PF, Tsuji H, Lloyd-Jones DM, et al. Association of hyperglycemia with reduced heart rate variability (The Framingham Heart Study). Am J Cardiol. 2000;86(3):309-12.

13. Watkins LL, Surwit RS, Grossman P, Sherwood A. Is there a glycemic threshold for impaired autonomic control? Diabetes Care. 2000;23(6):826-30.

14. Daviglus ML, Talavera GA, Aviles-Santa ML, Allison M, Cai J, Criqui MH, et al. Prevalence of major cardiovascular risk factors and cardiovascular diseases among Hispanic/Latino individuals of diverse backgrounds in the United States. JAMA. 2012;308(17):1775-84.

15. Heiss G, Snyder ML, Teng Y, Schneiderman N, Llabre MM, Cowie C, et al. Prevalence of metabolic syndrome among Hispanics/Latinos of diverse background: the Hispanic community health study/study of Latinos. Diabetes Care. 2014;37(8):2391-9.

16. Narayan KM, Boyle JP, Thompson TJ, Sorensen SW, Williamson DF. Lifetime risk for diabetes mellitus in the United States. JAMA 2003;290(14):1884-90.

17. Sorlie PD, Aviles-Santa LM, Wassertheil-Smoller S, Kaplan RC, Daviglus ML, Giachello AL, et al. Design and implementation of the Hispanic Community Health study/Study of Latinos. Ann Epidemiol. 2010;20(8):629-41.

18. Lavange LM, Kalsbeek WD, Sorlie PD, Aviles-Santa LM, Kaplan RC, Barnhart $J$, et al. Sample design and cohort selection in the Hispanic Community Health Study/Study of Latinos. Ann Epidemiol. 2010;20(8):642-9.

19. Heart rate variability. standards of measurement, physiological interpretation and clinical use; Task force of the European Society of Cardiology and the North American Society of Pacing and Electrophysiology. Circulation. 1996;93(5):1043-65.

20. American Diabetes A. Diagnosis and classification of diabetes mellitus. Diabetes Care. 2010;33(1):62-9.

21. Rautaharju PM, Wolf HK, Eifler WJ, Blackburn H. A simple procedure for positioning precordial ECG and VCG electrodes using an electrode locator. J Electrocardiol. 1976;9(1):35-40.

22. Rautaharju PM, Park L, Rautaharju FS, Crow R. A standardized procedure for locating and documenting ECG chest electrode positions: consideration of the effect of breast tissue on ECG amplitudes in women. J Electrocardiol. 1998;31(1):17-29.

23. Rothman KJ. Significance Questing. Ann Intern Med. 1986;105(3):445-7.

24. Albers JW, Brown MB, Sima AA, Greene DA. Nerve conduction measures in mild diabetic neuropathy in the early diabetes intervention trial: the effects of age, sex, type of diabetes, disease duration, and anthropometric factors. Tolrestat Study Group for the Early Diabetes Intervention Trial. Neurology. 1996;46(1):85-91.

25. Aaberg ML, Burch DM, Hud ZR, Zacharias MP. Gender differences in the onset of diabetic neuropathy. J Diabetes Complications. 2008;22(2):83-7.

26. Franconi F, Campesi I, Occhioni S, Tonolo G. Sex-gender differences in diabetes vascular complications and treatment. Endocr Metab Immune Disord Drug Targets. 2012;12(2):179-96. 
27. Nolan RP, Barry-Bianchi SM, Mechetiuc AE, Chen MH. Sex-based differences in the association between duration of type 2 diabetes and heart rate variability. Diabetes Vasc Dis Res. 2009;6(4):276-82.

28. Alvarez GE, Beske SD, Ballard TP, Davy KP. Sympathetic neural activation in visceral obesity. Circulation. 2002;106(20):2533-6.

29. Grassi G, Dell'Oro R, Facchini A. Quarti Trevano F, Bolla GB, Mancia $G$. Effect of central and peripheral body fat distribution on sympathetic and baroreflex function in obese normotensives. J Hypertens. 2004;22(12):2363-9.

30. Straznicky NE, Eikelis N, Lambert EA, Esler MD. Mediators of sympathetic activation in metabolic syndrome obesity. Curr Hypertens Rep. 2008;10(6):440-7.

31. Lindmark S, Lonn L, Wiklund U, Tufvesson M, Olsson T, Eriksson JW. Dysregulation of the autonomic nervous system can be a link between visceral adiposity and insulin resistance. Obes Res. 2005;13(4):717-28.

32. Paolisso G, Manzella D, Montano N, Gambardella A, Varricchio M. Plasma leptin concentrations and cardiac autonomic nervous system in healthy subjects with different body weights. J Clin Endocrinol Metab. 2000;85(5):1810-4.

33. Pieterse C, Schutte R, Schutte AE. Autonomic activity and leptin in Africans and whites: the SABPA study. J Hypertens. 2014;32(4):826-33.

34. Charles LE, Burchfiel CM, Sarkisian K, Li S, Miller DB, Gu JK, et al. Leptin, adiponectin, and heart rate variability among police officers. Am J Hum Biol. 2015;27(2):184-91.

35. Anderson EA, Hoffman RP, Balon TW, Sinkey CA, Mark AL. Hyperinsulinemia produces both sympathetic neural activation and vasodilation in normal humans. J Clin Investig. 1991;87(6):2246-52.

36. Vollenweider P, Randin D, Tappy L, Jequier E, Nicod P, Scherrer U. Impaired insulin-induced sympathetic neural activation and vasodilation in skeletal muscle in obese humans. J Clin Investig. 1994;93(6):2365-71.

37. Van De Borne P, Hausberg M, Hoffman RP, Mark AL, Anderson EA. Hyperinsulinemia produces cardiac vagal withdrawal and nonuniform sympathetic activation in normal subjects. Am J Physiol. 1999;276(1 Pt 2):R178-83

38. Plum L, Schubert M, Bruning JC. The role of insulin receptor signaling in the brain. Trends Endocrinol Metabol. 2005;16(2):59-65.

39. Schwartz MW, Figlewicz DP, Baskin DG, Woods SC, Porte D Jr. Insulin in the brain: a hormonal regulator of energy balance. Endocr Rev. 1992;13(3):387-414
40. Schwartz MW, Figlewicz DP, Woods SC, Porte D Jr, Baskin DG. Insulin, neuropeptide Y, and food intake. Ann N Y Acad Sci. 1993;692:60-71.

41. Schwartz MW, Woods SC, Porte D Jr, Seeley RJ, Baskin DG. Central nervous system control of food intake. Nature. 2000;404(6778):661-71.

42. Zieman SJ, Melenovsky V, Kass DA. Mechanisms, pathophysiology, and therapy of arterial stiffness. Arterioscler Thromb Vasc Biol. 2005;25(5):932-43.

43. Meerwaldt R, Links TP, Graaff R, Hoogenberg K, Lefrandt JD, Baynes JW, et al. Increased accumulation of skin advanced glycation end-products precedes and correlates with clinical manifestation of diabetic neuropathy. Diabetologia. 2005;48(8):1637-44.

44. Schroeder EB, Whitsel EA, Evans GW, Prineas RJ, Chambless LE, Heiss G. Repeatability of heart rate variability measures. J Electrocardiol. 2004;37(3):163-72.

45. de Bruyne MC, Kors JA, Hoes AW, Klootwijk P, Dekker JM, Hofman A, et al. Both decreased and increased heart rate variability on the standard 10-s electrocardiogram predict cardiac mortality in the elderly: the Rotterdam Study. Am J Epidemiol. 1999;150(12):1282-8.

46. Lombardi F. Clinical implications of present physiological understanding of HRV components. Card Electrophysiol Rev. 2002;6(3):245-9.

47. Brotman DJ, Bash LD, Qayyum R, Crews D, Whitsel EA, Astor BC, et al. Heart rate variability predicts ESRD and CKD-related hospitalization. J Am Soc Nephrol. 2010;21(9):1560-70.

48. Rautaharju PM, Kooperberg C, Larson JC, LaCroix A. Electrocardiographic abnormalities that predict coronary heart disease events and mortality in postmenopausal women: the Women's Health Initiative. Circulation. 2006;113(4):473-80.

49. Liao D, Carnethon M, Evans GW, Cascio WE, Heiss G. Lower heart rate variability is associated with the development of coronary heart disease in individuals with diabetes: the atherosclerosis risk in communities (ARIC) study. Diabetes. 2002;51(12):3524-31.

50. Dekker JM, Schouten EG, Klootwijk P, Pool J, Swenne CA, Kromhout D. Heart rate variability from short electrocardiographic recordings predicts mortality from all causes in middle-aged and elderly men. The Zutphen Study. Am J Epidemiol. 1997;145(10):899-908.

\section{Submit your next manuscript to BioMed Central and we will help you at every step:}

- We accept pre-submission inquiries

- Our selector tool helps you to find the most relevant journal

- We provide round the clock customer support

- Convenient online submission

- Thorough peer review

- Inclusion in PubMed and all major indexing services

- Maximum visibility for your research

Submit your manuscript at www.biomedcentral.com/submit
( Biomed Central 